\title{
Geleneksel Çocuk Oyunlarının Değerler Eğitimindeki Rolünün Sınıf Öğretmenlerinin Görüşleri Açısından Değerlendirilmesi
}

\section{Evaluation of the Role of Traditional Children's Games in Values Education in Terms of Classroom Teachers' Views}

\author{
Sibel OĞUZ HAÇAT ${ }^{\mathbb{D}}$, Doç. Dr., Kastamonu Üniversitesi Eğitim Fakültesi, soguz@kastamonu.edu.tr
}

Mehmet TOPAL ${ }^{\mathbb{D}}$ ，Bilim Uzmanı, Kastamonu Üniversitesi Sosyal Bilimler Enstitüsü, mehmettopal2013379@gmail.com

Oğuz Haçat, S. ve Topal, M. (2021). Geleneksel çocuk oyunlarının değerler eğitimindeki rolünün sınıf öğretmenlerinin görüşleri açısından değerlendirilmesi. Batı Anadolu Eğitim Bilimleri Dergisi, 12(2), 558-575.

Öz. Oyun yoluyla çocuk, kendini tanıma ve yaşadığı topluma karşı farkındalık oluştururken bir yandan da çocuğu topluma etkin kılar. Oyun toplumun yaşadığı kültürün özelliklerini yansıtmada, toplumların kültürel çözümleme ve yorumlama süreçlerinde önemlidir. Oyun oynarken bir taraftan eğlenen çocuk diğer yandan da toplumsal değerleri öğrenir. Bu çalışmanın amacı geleneksel çocuk oyunlarının değerler eğitimindeki rolünün sınıf öğretmenlerinin görüşleri açısından değerlendirmektir. Çalışma grubu, Gaziantep il merkezinde görev yapan 30 sınıf öğretmenidir. Çalışma, nitel araştırma yöntemlerinden durum çalışma modeli ile gerçekleşmiştir. Veriler, yarı yapılandııımış görüşme formu ile toplanmışır. Çalışmada elde edilen veriler içerik analizi ile çözümlenmiştir. Araştırma sonucunda, öğretmenler, geleneksel çocuk oyunlarını değerler eğitimi açısından önemli gördüklerini belirtmektedir. Öğretmenler; kültürün gelecek kuşaklara aktarımı, çocukların yardımlaşma, dürüstlük, saygı, sevgi, sorumluluk gibi değerleri öğrenmeleri, çocuklar arasında olumlu iletişimin gelişmesi, işbirlikçi öğrenmeyi sağlaması, farklılıklara saygı duymayı, değerlerin oyunlarla eğlenceli hale getirilmesi gibi sebeplerle geleneksel çocuk oyunlarını değerler eğitimi açısından öğretmenler önemli gördüklerini ifade etmektedir. Geleneksel çocuk oyunlarıyla öğrencilerin birden fazla değeri kazandıkları, geleneksel çocuk oyunlarının ders kitaplarında yeterli seviyede bulunmadığı ve değerler eğitimi açııından okul öncesi dönemde de yer verilmesi gerektiği öğretmenler tarafından belirtilmiştir. Geleneksel çocuk oyunlarıyla öğretmenlerin çocuklarda en fazla kazandırmayı amaçladıkları değerler sevgi, adalet, saygı, sorumluluk, dayanışma, yardımseverlik, dürüstlük ve eşitliktir.

Anahtar Kelimler: Oyun, Değer, Eğitim, Çocuk.

Abstract. Through play, the child creates awareness of himself and the society he lives in, while at the same time making the child active in the society. Play is important in reflecting the characteristics of the culture in which the society lives and in the cultural analysis and interpretation processes of societies. While playing the game, the child who has fun on the one hand learns the social values on the other hand. The aim of this study is to evaluate the role of traditional children's games in values education in terms of the opinions of classroom teachers. The working group is 30 classroom teachers working in Gaziantep city center. The study was carried out with the case study model, one of the qualitative research methods. The data were collected using a semistructured interview form. The data obtained in the study were analyzed by content analysis. As a result of the research, teachers state that they see traditional children's games as important in terms of values education. Teachers; Teachers express that they see traditional children's games as important in terms of values education for reasons such as the transfer of culture to future generations, children learning values such as cooperation, honesty, respect, love, responsibility, development of positive communication among children, providing cooperative learning, respecting differences, making values fun with games. . Teachers stated that students gain more than one value with traditional children's games, that traditional children's games are not found in 
textbooks at a sufficient level, and that they should be included in the preschool period in terms of values education. The values that teachers aim to make children gain the most through traditional children's games are love, justice, respect, responsibility, solidarity, benevolence, honesty and equality.

Keywords: Game, Value, Education, Children.

\section{Extended Abstract}

Introduction. Traditional children's games, which carry the functions of socializing, having fun, having general knowledge as well as protecting values, fight against a subliminal threat that is altered by technology. Traditional children's games, which are one of the greatest enemies of cultural degeneration, are an important tool that conveys the consciousness of being a family, society and a nation to fresh minds. The values that ensure the survival of the society connect the individuals who make up the society. It is an undeniable fact that it is important to create a social identity by learning social rules through values education and the basic issues of moral philosophy, which is accepted as good and bad in society. On the way from being an individual to being a citizen, from being a family to being a part of a nation, the basic traditional children's games are laid. Otherwise, in critical age ranges, it is observed that there are no values belonging to the family, society and the nation in which they live in individuals who receive values education only with knowledge or not at all.

Method. In the study, one of the qualitative research models, case study design was used. Case study is a research method that examines the phenomenon in real life, is used in cases where the connection between the phenomenon and the content is not drawn with sharp lines and there is more than one evidence or data available. In the study, the case study design was chosen in order to conduct an in-depth study by examining the effect of traditional children's games on values education in line with teachers' opinions.

Data collection. After the interview form was prepared to evaluate the role of traditional children's games in values education in terms of the opinions of classroom teachers, classroom teachers were determined in accordance with the criterion sampling method. In the 2019-2020 academic year, interviews were made with 30 volunteer classroom teachers working in Gaziantep and meeting the specified criteria. The interviews were held with the participants in the areas where the appropriate place and time were determined. It has been said that the information will not be shared with anyone and will not be used for any other purpose. Questions in the semi-structured interview form were asked. Interviews with the participants were conducted face to face. Interview forms are numbered as Ö.1, Ö.2, ......, Ö.30 by giving a code number. The questions in the form were asked to the participants in order, and their answers were recorded by the researcher.

Results and Discussion. All of the teachers who make up the working group state that they see traditional children's games as important in terms of values education. Teachers; To the conclusion that teachers see traditional children's games as important in terms of values education for reasons such as the transfer of culture to future generations, children's learning values such as cooperation, honesty, respect, love, responsibility, development of positive communication among children, providing collaborative learning, respecting differences, and making values fun with games has been reached. Similar results have been reached that teachers see traditional children's games as important in terms of values education. In their study, Sümbüllü and Altınışı (2016) concluded that 
traditional children's games are the place where traditional children's games prepare children for the future, presenting social values in a safe and easy way by presenting social values.

It was stated by the majority of the participants that traditional children's games were played in the preschool period in terms of values education. The reasons of the teachers who think that education should be played in the pre-school period; The period in which children learn faster and permanently, when their personality development develops, when the culture is internalized, when psychomotor and affective skills are acquired, when respect for individual differences is gained, when the awareness of being a group is gained, when the child makes life meaningful, traditional children's games are It was concluded that it would be positive to play. In his research, Bay (2018) found that national games can be easily given within the framework of the preschool education program and that games, which are an important element of national culture, contribute positively to the development of children.

It was concluded that students gain more than one value with traditional children's games. The values that teachers observe what they have gained by students are respect, love, justice, solidarity, solidarity, honesty, equality, responsibility, aesthetics and peace. Teachers stated that the values they observe with traditional children's games are gained more easily. Ministry of Education [MEB] (2018) values in social studies curriculum; justice, family unity, independence, peace, scientificity, diligence, solidarity, sensitivity, honesty, aesthetics, equality, freedom, respect, love, responsibility, thrift, patriotism and benevolence.

The majority of teachers do not find traditional children's games in textbooks sufficiently. Teachers who do not find a sufficient level; The content of the textbook should be rich in terms of play, more game activities should be included, game activity cards, enriching leisure activities with games, being theoretically oriented to practice, opening courses related to traditional children's games and following an interdisciplinary approach. Ünal (2013) found in his study that there are more cultural acquisitions in the 4 th grade social studies curriculum. It has been seen that social studies textbooks and workbooks do not include examples of all categories of folk culture elements.

The values that teachers aim to make children gain the most through traditional children's games are love, justice, respect, responsibility, solidarity, benevolence, honesty and equality. Teachers, with the values they aim to bring in students through traditional children's games; It has been concluded that it will provide benefits for children such as providing unity and solidarity, transferring culture, learning values permanently, respecting differences, taking duties and responsibilities, producing practical solutions to problems and feeling belonging to the group. Çengelci, Hancl, and Karaduman (2013) concluded in their study that the values that teachers try to gain in school are love, respect, tolerance, solidarity and responsibility. 


\section{Giriş}

Oyun ve öğrenme, çocuğun hayatında bir bütünlük ve süreklilik gösteren bir süreçtir. Oyun oynamak onların duyu, entelektüel ve sosyal becerilerini anlamalarına ve uygulamalarına yardımcı olur. Oyun aynı zamanda eğlenceli bir şekilde yapılmalıdır ki oyun etkinlikleri çocuklarda bir öğrenme süreci ile sonuçlanmalıdır. Oyun çocuklarda hızlı, kalıcı ve etkili öğrenmeler sağlayarak (Aypay, 2016) yetişkin yaşamına hazırlar (Esen, 2008). Bu bakımdan oyun çocuklara başka yöntemlerle kazandırılmakta zorlanılan veya zaman alan öğrenmeleri (Aypay, 2016) toplumsal kuralları ve ahlaki değerleri (Esen, 2008) hızlı bir şekilde içselleştirmelerine yardımcı olur. Dünya üzerinde bulunan bütün canlıların yaşam amaçları incelendiğinde hepsinde ortak gaye olarak öz varlığını devam ettirmek ve bu maksatla bilgi ve deneyimlerini sonraki nesillere aktarılması göze çarpmaktadır. Bilinen en gelişmiş varlık olan insanda ise bu bilgilerin toplumsal rollerin aktarılması amacıyla varlığını devam ettirmeye yarayan duyuşsal bilgiler ve gelişimi sağlayan bilişsel bilgilerden oluşmaktadır. Kültür bir toplumda uygulanan kapsamlı bir bütünlük olduğundan eğitim ve kültür insan hayatında ayrılmaz bir bütündür (Zayyadi, Hasanah ve Surahmi, 2018). Bir birey olarak insan duyuşsal bilgilerini kullanarak kültür ve sahip olduğu değerleri muhafaza etme ve aktarma vazifesine doğuştan sahiptir. Her toplum içinde barındırdığı bireylere gelenek-göreneklerini, değerlerini, kültürlerini aktarmaya çalışır (Sümbüllü ve Altınışık, 2016). Toplumun kültürünü öğrenmek aynı zamanda toplumda var olan değerleri öğrenmektir. Yaşamı anlamlandırma, uygun kararlar alma, toplumun içinde bulunduğu kültüre uygun davranışlar göstermede değerler önemli bir rehberdir (Aypay, 2016). Bu amaçla da çeşitli argümanlar zamanla kendiliğinden ortaya çıkmıştır. Ve yüzyıllar boyunca varlıklarını devam ettirmişlerdir. Bunlardan en önemlilerinden biri geleneksel çocuk oyunlarıdır. Geleneksel oyunlar bir halkın somut olmayan mirası, kültürünün maddi olmayan kısmını kapsar. Bunlar; masallar, anlatılar, şarkılar, müzik ve geleneksel olarak sözlü yollarla aktarılan tüm bilgileri içerir. Geleneksel oyunlar zengin bir kültürel miras değerine sahiptir. Onlar, atalardan gelen bazı bilgileri gelecek nesillere aktarmada, grup ve aile duygusunu geliştiren bir kaynak oluşturmada için önemli bir araçtır (Ghosh, 2015).

Toplumlar kültürlerini gelecek nesillere aktarma işlevini oyun ile yapar (Sümbüllü ve Altınışık, 2016). Çocuklar için oyun toplumun kültürel değerlerini öğrenme (Apay, 2016) kültürün devamlılığını sağlama, kültürel mirası muhafaza etme gibi özelliklerdir (Bay, 2018). Oyun değer kazandırmanın en iyi yolu olarak görülür. Toplumun değerlerine geleneksel oyunlarda sıkça rastlanır. Oyunlar toplumun değerleri hakkında bilgi verir. Geleneksel çocuk oyunları kültürün korunmasında, gelecek nesillere aktarılmasında önemli bir yeri olan halk bilgisi ürünleridir (Korkutan ve Fedakar, 2016). Bu nedenle çocukluk sürecinde oynanan oyunlar kültürün paylaşılmasına, değerlerin öğrenilmesine, zengin ve erdemli bir karakter oluşturmaya yardımcı olmaktadır (Aypay, 2016). Aynı zamanda oyun başkalarına saygı duyma, hem kendi hakkını hem de diğer insanların hakkını koruma, sorumluluklarını yerine getirme, karar alma, işbirliği gibi toplumsal kuralları öğrenmede (Anılan, Girmen, Öztürk ve Koçkar, 2004) ortak kültürel değerleri içselleştirip davranışlara dönüştürmede önemli bir yere sahiptir (Aypay, 2016). Değerleri koruyucu işlevinin yanında sosyalleşme, eğlenme genel geçer bilgi sahibi olma işlevlerini de taşıyan geleneksel çocuk oyunları teknoloji vasıtasıyla başkalaşan subliminal bir tehdide karşıda mücadele etmektedir. Kültür yozlaşımının en büyük düşmanlarından biri olan 
geleneksel çocuk oyunları salt bilgiyle aktarılamayacak aile, toplum ve millet olma şuurunu taze dimağlara aktaran önemli bir araçtır.

Toplumun ayakta kalmasını sağlayan değerler, toplumu oluşturan bireyleri birbirine bağlamaktadır. Değerler eğitimiyle toplumsal kuralları, toplumda iyi-kötü olarak kabul edilen ahlak felsefesinin temel konularını öğrenerek toplumsal bir kimlik oluşturmada önemi yadsınamaz bir gerçektir. Birey olmaktan vatandaş olmaya, aile olmaktan bir milletin parçası olmaya giden yolda temel geleneksel çocuk oyunları ile atılmaktadır. Aksi durumda yani kritik yaş aralıklarında değerler eğitimini salt bilgiyle alan ya da hiç almayan bireylerde aileye, topluma ve içinde yaşadığı ulusa ait değerlerin bulunmadığı göze çarpmaktadır. Aidiyet yaşamayan bireylerinde öze dönük ya da topluma katkı sağlaması beklenemez. Değerleri gelecek nesillere aktarmada eğitim, okul ve sınıf ortamı önemlidir. Toplum, genç bireylere geçmişten günümüze kadar var ettiği birikimini okul aracılığıyla aktararak geleceğine yön verdiği belirtilmektedir. Geleneksel oyunlar insanoğlunun sosyal yaşamının ayrılmaz bir parçası olduğunu göstermektedir. O bölgelerin iklimine ve coğrafyasına bağıı olarak farklı bölgelerde çeşitli oyunlar ortaya çıkmıştır. Öte yandan geleneksel oyunlar, ritüelleri gözlemlemek için dini ve efsanevi renklerle dolu eylemleri içermektedir. Antik çağda, doğunun belli başlı ülkeleri arasında eğitim sistemlerinde oyuna ağılık veren en büyük ülke Pers'ti. Persler oyunu yalnızca boş zaman veya eğlence aracı olarak görmediler; daha ziyade, oyunu insani erdemleri, yüce gönüllülüğü, fedakarlı̆ı̆, dürüstlüğü ve iyi davranışı yaymak için bir ahlaki davranış ritüeli olarak görmüşlerdir. Buna ek olarak, Persler oyunu kararlıık, şevk, korkaklığa karşı nefret, ulusa destek, asalet, cömertlik ile yakından ilişkilendirdiler (Dehkordı, 2017). Çocuk oyunlarının sadece eğlence amaçlı oyunlar olmaması bunların temel bir anlama sahip oldukları görülmektedir. Bu oyunlarla eski günlerde neler olduğu hakkında birçok şey öğrenme, toplumsal kültürün öğrenimi, kültürel farkındalık, kültürle yeniden bağlantı kurma, bölgenin geleneksel dil grubu olan ifadeleri öğrenme kültürel önem duygusu yaratma, çocuklarda güçlü bir kişisel kimlik duygusu geliştirme ve saygının en önemli noktalarını oluşturmaktadır. Çocuklara geleneksel oyunlarla meşgul etme fırsatı verilmesi sosyo-kültürel gelişimlerinin yanında, öğretim programlarının felsefi yönünü de desteklemektedir (Thompson, Meldrum ve Sellwood, 2014).

İlgili çalışmalara bakıldığında geleneksel çocuk oyunlarının değerler eğitimindeki rolünün sınıf öğretmenlerinin görüşleri açısından değerlendirilmesi ile ilgili az sayıda çalışmanın var olduğu söylenebilir. Yapılan araştırmalar incelendiğinde genellikle geleneksel çocuk oyunlarının değerler eğitimindeki önemi, evrensel ve eğitsel değeri, modern eğitimdeki yeri, oyunların tarihi, nasıl oynandığı, oyunların eğitimdeki kalıcılığı (Anılan vd., 2004; Dharmamulya, 2005; Emir vd., 2006; Esen, 2008; Çenegelci, 2013; Kurniawati vd., 2014; Thompson vd., 2014; Ghosh, 2015; Sümbüllü ve Altınışık, 2016; Aypay, 2016; Korkutan ve Fedakar, 2016; Dehkordı, 2017; Öz Pektaş, 2017; Bay, 2018; Zayyadi vd., 2018; Cop ve Kablan, 2018) gibi başlıklarda incelendiği görülmüştür. Ancak alan yazında eğitim sürecinin ilk basamağı olan ilkokul döneminde birçok bilgi ve becerinin öğrenildiği, içselleştirildiği ve öğrenilenlerin en kalıcı olduğu zamanda (Samancı ve Uçan, 2015) geleneksel çocuk oyunlarının değerler eğitimine etkisine ilişkin sınıf öğretmenlerinin görüşleri ile ilgili bir çalışmaya rastlanılmamıştır. Bu çalışma da alan yazında boşluk oluşturan geleneksel çocuk oyunlarının değerler eğitimine etkisini öğretmen bakış açısıyla değerlendirme ihtiyacından kaynaklanmıştır.

Sınıf öğretmenlerinin görüşleri doğrultusunda geleneksel çocuk oyunlarının değerler eğitimine etkisine ilişkin değerlendirme yaparak oyunların değer kazandırmaya etkisi ve verimliliği ile 
ilgili uygulamaya dönük fikirler elde etmek amacıyla yapılmıştır. Araştırmada "Geleneksel çocuk oyunlarının değerler eğitimindeki rolünde sınıf öğretmenlerinin görüşleri nelerdir?” sorusu araştırmanın problem sorusunu oluşturmaktadır. Amaç çerçevesinde şu araştırma sorularına cevap aranmıştır:

1-Sınıf öğretmenlerinin görüşlerine göre çocuk oyunlarının değerler eğitimi açısından önemi nasıldır? 2-Sınıf öğretmenleri çocuk oyunlarının değerler eğitimine olumlu yönde katkı sağlayabilmesi için eğitimin hangi basamağından itibaren başlaması gerektiğini düşünmektedirler?

3-Sınıf öğretmenleri çocuk oyunlarıyla öğrencilerin kazandıklarını gözlemledikleri değerler hangileridir?

4-Sınıf öğretmenleri çocuk oyunlarını ders kitaplarında yeterli ölçüde buluyorlar mı? Yeterli görülmemesi halindeki çözüm önerileri nelerdir?

5-Sınıf öğretmenleri çocuk oyunlarıyla öğrencilere hangi değerleri kazandırmayı amaçlamaktadır? Kazandırmayı amaçladıkları değerlerin öğrencilere yararları nelerdir?

\section{Araştırma Modeli}

\section{Yöntem}

Çalışmada nitel araştırma modellerinden durum çalışması deseni uygulanmıştır. Durum çalışması, olguyu gerçek yaşamı içinde inceleyen, içerik ve olgu arasındaki bağlantının keskin çizgilerle çizilmediği ve birden çok ispat yada verinin hazır halde bulunduğu durumlarda kullanılan araştırma yöntemidir (Yıldırım ve Şimşek, 2005). Araştırmada durum çalışması deseni geleneksel çocuk oyunlarının değerler eğitimine etkisini öğretmen görüşleri doğrultusunda inceleyerek derinlemesine bir araştırma yapmak amacıyla tercih edilmiştir.

\section{Çalışma Grubu}

Araştırmanın çalışma grubunu Gaziantep il merkezine görev yapmakta olan 30 sınıf öğretmeni oluşturmaktadır. Araştırma grubunun belirlenmesinde amaçsal örnekleme yöntemi, türlerinden ölçüt (kriter) örnekleme yöntemi kullanılmıştır. Amaçsal örnekleme, seçkisiz olmayan bir örnekleme yöntemi olup, araştırmanın hedefine bağlı olarak bilgi bakımından zengin durumlar alınarak derinlemesine bir inceleme yapılmasını sağlayan yöntemdir. (Büyüköztürk, Kılıç Çakmak, Akgün, Karadeniz, ve Demirel 2011). Öğretmenlerin geleneksel çocuk oyunlarının değerler eğitimine etkisine ilişkin görüşlerine yönelik derinlemesine bir araştırma yapılmak istenmesinden dolayı çalışma amaçsal örnekleme yöntemi seçilmiştir. Ölçüt (kriter) örnekleme yönteminde, araştırmacılar çalışmada yer alacak katılımcıları belli ölçütler çerçevesinde seçerler (Büyüköztürk, vd. 2011). Bu araştırmanın örneklemindeki ölçüt "değerler eğitimi seminer programına en az bir defa katılan sınıf öğretmenleri” olarak belirlenmiştir.

\section{Veri Toplama Aracı}

Bu çalışmada yarı yapılandırılmış görüşme tekniği ile veriler elde edilmiştir. Bu çalışmada görüşme, kişilerin konuyla ilgili kendi bakış açıları doğrultusunda tutum ve deneyimlerini (Karataş, 2015) duygu, düşünce ve görüşlerini doğru bir şekilde öğrenmek, anlamak için tercih edilmiştir. Yarı yapılandırılmış görüşme tekniğinde görüşme içerisinde belirli seviyede standartlığa sahip olması aynı 
zamanda araştırmacı farklı sorularla görüşmenin akışını etkileyerek, bireylerin vermiş oldukları cevapları ayrıntılı şekilde ifade etmelerini sağladığı esneklik (Türnüklü, 2000) sebebiyle bu teknik tercih edilmiştir. "Geleneksel Çocuk Oyunlarının Değerler Eğitimindeki Rolünün Sınıf Öğretmenlerinin Görüşleri Açısından Değerlendirilmesi Görüşme Formunun”hazırlanmasına yönelik geçerliliğini arttırmak amacıyla ilgili literatür taranarak soru taslağı oluşturulmuş, üç uzmanın görüşüne sunulmuştur. (Bir sınıf öğretmeni, bir Türkçe öğretmeni, bir eğitim bilim uzmanı). Yapılan bir takım düzeltmelerden sonra araştırmacılar tarafından çalışmanın amacına uygun şekilde beş soru içeren görüşme formu hazırlanmıştır. Hazırlanan görüşme formunda yer alan soruların güvenirliğini random örnekleme yöntemiyle farklı okullarda görev yapan dört sınıf öğretmenine uygulanarak sağlanmıştır. Görüşme formunda yer alan sorular çalışmanın amacına uygun olduğuna karar verildikten sonra çalışma grubunda yer alan öğretmenlere uygulanmıştır.

\section{Verilerin Toplanması}

Geleneksel çocuk oyunlarının değerler eğitimindeki rolünün sınıf öğretmenlerinin görüşleri açısından değerlendirilmesi görüşme formunun hazırlanmasından sonra ölçüt örnekleme yöntemine uygun şekilde sınıf öğretmenleri belirlenmiştir. 2019- 2020 eğitim öğretim yılında Gaziantep’te Görev yapan ve belirtilen ölçütleri sağlayan gönüllü 30 sınıf öğretmeni ile görüşmeler yapılmıştır. Görüşmeler katılımcılarla uygun yer ve saatin belirlendiği alanlarda yapılmıştır. Bilgilerin kimseyle paylaşılmayacağı ve başka herhangi bir amaca yönelik kullanılmayacağı söylenmiştir. Yarı yapılandırılmış görüşme formunda bulunan sorular sorulmuştur. Katılımcılarla görüşmeler yüz yüze gerçekleştirilmiştir. Görüşme formlarına, kod numarası verilerek, Ö.1, Ö.2,......,Ö.30 biçiminde numaralandırılmıştır. Formda yer alan sorular katılımcılara sıra ile sorulmuş verilen yanıtlar araştırmacı tarafından kaydedilmiştir.

\section{Verilerin Analizi}

$\mathrm{Bu}$ araştırmada verilerin analizi içerik analizi yaklaşımı kullanarak yapılmıştır. İçerik analizi birbirine benzer şekilde olan veriler bir araya toplanarak okuyucunun anlayacağı şekilde düzenlenmesi ve yorumlanmasıdır (Yıldırım ve Şimşek, 2005). Bu çalışmada içerik analizi verileri kodlama, temaları uygun şekilde belirleme, düzenleme, tanımlama ve yorumlama (Yıldırım ve Şimşek, 2005) verileri derinlemesine inceleme, benzer nitelikte olan verileri bütüncül olarak bir araya toplayarak okuyucunun anlayacağı şekilde yorumlanabilmesi (Karataş, 2015) sebebiyle tercih edilmiştir. Görüşme sonucunda veriler düzenlenerek gruplandırımış, tablo halinde gösterilmiştir. Veriler oluşturulan tablolarda frekans (f) ve yüzde (\%) değerleri ile gösterilmiştir. Veriler gerekli yerlerde doğrudan alıntılar desteklenmiştir. 


\section{Bulgular}

Geleneksel çocuk oyunlarını değerler eğitimi açısından önemli görüyor musunuz? Önemli görmeniz halinde bunun sebepleri nelerdir?" Sorusuna yönelik Tablo 1 ve Tablo 2 'de görüşler doğrultusunda elde edilen bulgulara yer verilmiştir.

Tablo 1. Öğretmenlerin geleneksel çocuk oyunlarını değerler eğitimi açısından önemine ilişkin görüşlerinin analiz sonuçları

\begin{tabular}{lcc}
\hline Önemlilik durumu & $\mathbf{F}$ & $\mathbf{\%}$ \\
\hline Evet & 30 & 100 \\
\hline Hayır & 0 & 0 \\
\hline Toplam & 30 & 100 \\
\hline
\end{tabular}

Tablo 2. Öğretmenlerin geleneksel çocuk oyunlarını değerler eğitimi açısından önemli görülmesinin sebeplerine ilişkin görüşlerini ifade eden yanıtların frekans ve dağıım tablosu

\begin{tabular}{llc}
\hline Önemli görülmesinin sebebi & F & $\%$ \\
\hline Kültürün gelecek kuşaklara aktarımı & 8 & 26.6 \\
\hline $\begin{array}{l}\text { Çocukların yardımlaşma, dürüstlük, } \\
\text { saygı, sevgi, sorumluluk gibi } \\
\text { değerleri öğrenmeleri }\end{array}$ & 7 & 23.3 \\
\hline $\begin{array}{l}\text { Çocuklar arasında olumlu iletişimin } \\
\text { gelişmesi }\end{array}$ & 5 & 16.6 \\
\hline $\begin{array}{l}\text { İşrlikçi öğrenmeyi sağlama } \\
\text { Farklılıklara saygı duyma }\end{array}$ & 4 & 13.3 \\
\hline $\begin{array}{l}\text { Değerlerin oyunlarla eğlenceli hale } \\
\text { getirilmesi }\end{array}$ & 3 & 10 \\
\hline Toplam & 2 & 6.6 \\
\hline
\end{tabular}

Tablo 1.'de ifade edildiği üzere geleneksel çocuk oyunlarını değerler eğitimi açısından önemli gördüğünü söyleyen öğretmenlerin oranı \% 100'dür.Öğretmenler geleneksel çocuk oyunlarını değerler eğitimi açısından önemli olduğunu düşünmektedirler.

Geleneksel çocuk oyunlarını değerler eğitimi açısından önemli görmelerine sebep olan durumları öğretmenler \% 26.6'sı kültürün gelecek kuşaklara aktarımı, \% 23.3 çocukların yardımlaşma, dürüstlük, saygı, sevgi, sorumluluk gibi değerleri öğrenmelerini, \% 16.6 çocuklar arasında olumlu iletişimin gelişmesini, \% 13.3 işbirlikçi öğrenmeyi sağlamasını, \% 10 farklııklara saygı duymayı, \% 6.6 değerlerin oyunlarla eğlenceli hale getirilmesi gibi sebeplerle geleneksel çocuk oyunlarını değerler eğitimi açısından öğretmenler önemli gördüklerini ifade etmektedirler. En fazla 
önemli görülen sebep \% 26.6 ile kültürün gelecek kuşaklara aktarımıdır. Öğretmenler genel olarak geleneksel çocuk oyunlarını kültürün gelecek kuşaklara aktarımında önemli olduğunu düşünmektedirler.

Aşağıda geleneksel çocuk oyunlarını değerler eğitimi açısından önemli gördüğünü düşünen öğretmen görüşlerinden örnekler verilmektedir:

Ö.17."Evet önemli görüyorum. Çünkü geleneksel çocuk oyunlarıyla birlik, takım olma ve grup çalışması daha çok oluyor. Bu da yardımlaşma, saygı, sevgi, dürüstlük, sorumluluk gibi değerlerin ön plana çıkmasını sağlıyor."

Ö.8. "Değerler eğitimi açısından oldukça önemli buluyorum. Çünkü; teknolojinin hızla geliştiği günümüzde bilgisayar oyunları çocuklarımızı sanal ortamın içine alıp sosyal çevreden ve değerlerimizden uzaklaştırmaktadır. Geleneksel çocuk oyunları ise kültürümüzün gelecek nesillere aktarılmasını, öğretilmesini sağlayan en önemli araçlardan birisidir. "

Geleneksel çocuk oyunlarının eğitimin hangi basamağından itibaren oynatılması değerler eğitimi açısından olumlu etki yapar? Verdiğiniz cevabın nedenini açıklar mısınız? Sorusuna yönelik Tablo 3 ve Tablo 4'de görüşler doğrultusunda elde edilen bulgulara yer verilmiştir.

Tablo 3. Öğretmenlerin geleneksel çocuk oyunlarının eğitimin hangi basamağından itibaren oynatılması değerler eğitimi açısından olumlu etki yaptığını ifade eden görüşlerine ait yanıtların frekans ve dağılım tablosu

\begin{tabular}{lll}
\hline Eğitim basamağı & $\mathbf{f}$ & \% \\
\hline Okul öncesi & 27 & 90 \\
\hline Diğer & 3 & 10 \\
\hline Toplam & 30 & 100 \\
\hline
\end{tabular}

Tablo 4. Geleneksel çocuk oyunlarının eğitimin hangi basamağından itibaren oynatılması ile ilgili verilen cevabın nedenini ile ilgili görüşlerini ifade eden yanıtların frekans ve dağılım tablosu

\begin{tabular}{lll}
\hline Verilen cevabın nedeni & $\mathbf{f}$ & $\%$ \\
\hline $\begin{array}{l}\text { Çocukların daha hızlı ve kalıcı } \\
\text { öğrendiği dönem }\end{array}$ & 5 & 16.6 \\
\hline $\begin{array}{l}\text { Kişilik gelişiminin geliştĭ̆i } \\
\text { zaman }\end{array}$ & 5 & 16.6 \\
\hline $\begin{array}{l}\text { Kültürün içselleştirilmesinin } \\
\text { sağlandığı dönem }\end{array}$ & 4 & 13.3 \\
\hline $\begin{array}{l}\text { Psikomotor ve duyuşsal } \\
\text { becelerin kazanıldı̆ı zaman }\end{array}$ & 3 & 10 \\
\hline $\begin{array}{l}\text { Bireysel farklılıklara saygının } \\
\text { kazanıldığı dönem }\end{array}$ & 3 & 10 \\
\hline $\begin{array}{l}\text { Grup olma bilincinin } \\
\text { kazanıldığı zaman }\end{array}$ & 3 & 10 \\
\hline $\begin{array}{l}\text { Çocuğun hayatı } \\
\text { anlamlandırdığı zaman }\end{array}$ & 2 & 6.6 \\
\hline Diğer & 3 & 10 \\
\hline Toplam & 30 & 100 \\
\hline
\end{tabular}


Öğretmenlerin \% 90’ geleneksel çocuk oyunlarının okul öncesi dönemde oynatılmasını değerler eğitimi açısından olumlu olacağını düşünmektedir. Diğer eğitim basamaklarında oynatılması gerektiğini düşünen öğretmenlerin oranı \% 10'dur.

Verilen cevabın sebebi ile ilgili öğretmen görüşleri tablo 4'deki gibidir. Okul öncesi dönemde öğretmenlerin \% 16.6'sı çocukların daha hızlı ve kalıcı öğrendiği dönem, \% 16.6'sı kişilik gelişiminin geliştiği zaman, \% 13.3 kültürün içselleştirilmesinin sağlandığı dönem, \% 10 psikomotor ve duyuşsal becelerin kazanıldığı zaman, \% 10 bireysel farklılıklara saygının kazanıldığı dönem, \% 10 grup olma bilincinin kazanıldığı zaman, \% 6.6 çocuğun hayatı anlamlandırdığı zaman, \% 10'u da diğer sebeplerden dolayı geleneksel çocuk oyunlarının okul öncesi dönemde oynatılmasının olumlu olacağını düşünmektedirler. Öğretmenlerin görüşlerine göre okul öncesi dönemde oynatılmasını en fazla \% 16.6 ile çocukların daha hızlı ve kalıcı öğrendiği dönem, \% 16.6 ile kişilik gelişiminin geliştiği zaman olduğu için olumlu etki yaratacağını ifade etmişlerdir.

Aşağıda geleneksel çocuk oyunlarının okul öncesi dönemde oynatılmasını değerler eğitimi açısından olumlu olacağını düşünen öğretmen görüşlerinden örnek verilmektedir:

Ö.19. "Okul öncesi dönemde başlatılması gerekmektedir. Özellikle 3-6 yaş arasındaki çocukların hızlı ve kalıcı öğrendiği zaman olup hayata aktardığı bir dönemdir. "

Geleneksel çocuk oyunlarıyla öğrencilerde kazandıklarını gözlemlediğiniz değerler hangileridir? Sorusuna yönelik Tablo 5’de görüşler doğrultusunda elde edilen bulgulara yer verilmiştir.

Tablo 5. Geleneksel çocuk oyunlarıyla öğrencilerde kazandıklarını gözlemlediğiniz değerlerle ilgili öğretmen görüşlerini ifade eden yanıtların frekans ve dağılım tablosu

\begin{tabular}{lll}
\hline Değerler & $\mathbf{f}$ & $\%$ \\
\hline Saygı & 9 & 14.7 \\
\hline Sevgi & 8 & 13.1 \\
\hline Adalet & 8 & 13.1 \\
\hline Dayanışma & 7 & 11.4 \\
\hline Yardımlaşma & 6 & 9.8 \\
\hline Dürüstlük & 5 & 8.1 \\
\hline Eşitlik & 5 & 8.1 \\
\hline Sorumluluk & 5 & 8.1 \\
\hline Estetik & 3 & 4.9 \\
\hline Barış & 2 & 3.2 \\
\hline Diğer & 3 & 4.9 \\
\hline Toplam & 61 & 100 \\
\hline
\end{tabular}

Öğretmenler geleneksel çocuk oyunlarıyla öğrencilerin birden fazla değeri kazandıklarını gözlemlemişlerdir. En fazla gözlemledikleri değerler ise; -sırası ile- saygı, sevgi, adalet, dayanışma, yardımlaşma, dürüstlük, eşitlik, sorumluluk, estetik ve barıştır. Öğretmenler geleneksel çocuk oyunlarıyla tablo 5'de ifade edilen değerlerin daha kolay kazanılacağını düşünmektedirler. 
Geleneksel çocuk oyunlarını ders kitaplarında yeterli ölçüde buluyor musunuz? Yeterli görmemeniz halinde çözüm önerileriniz nelerdir? Sorusuna yönelik Tablo 6 ve Tablo 7'de görüşler doğrultusunda elde edilen bulgular yer almaktadır.

Tablo 6. Öğretmenlerin geleneksel çocuk oyunlarını ders kitaplarında yeterliliği ile ilgili görüşlerini ifade eden yanıtların frekans ve dağılım tablosu

\begin{tabular}{lll}
\hline Ders kitaplarında olan yeterlilik & $\mathbf{f}$ & $\mathbf{\%}$ \\
\hline Evet & 8 & 26.6 \\
\hline Hayır & 22 & 73.3 \\
\hline Toplam & 30 & 100 \\
\hline
\end{tabular}

Tablo 7. Öğretmenlerin geleneksel çocuk oyunlarını ders kitaplarında yeterli görmemeleri halinde sunmuş oldukları çözüm önerilerinin ifade edildiği yanıtların frekans ve dağııım tablosu

\begin{tabular}{lll}
\hline Çözüm önerileri & $\mathbf{f}$ & $\%$ \\
\hline $\begin{array}{l}\text { Ders kitabının içeriği oyun } \\
\text { yönünden zengin olmalı }\end{array}$ & 7 & 23.3 \\
\hline $\begin{array}{l}\text { Daha fazla oyun etkinliklerine } \\
\text { yer verilmeli }\end{array}$ & 6 & 20 \\
\hline $\begin{array}{l}\text { Oyun etkinlik kartlarının } \\
\text { olması }\end{array}$ & 4 & 13.3 \\
\hline $\begin{array}{l}\text { Serbest zaman etkinliklerinin } \\
\text { oyunlarla zenginleştirilmesi }\end{array}$ & 4 & 13.3 \\
\hline $\begin{array}{l}\text { Teorikten uygulamaya dönük } \\
\text { olması }\end{array}$ & 3 & 10 \\
\hline $\begin{array}{l}\text { Geleneksel çocuk oyunlarıyla } \\
\text { ilgili kurslar açıması }\end{array}$ & 2 & 6.6 \\
\hline $\begin{array}{l}\text { Disiplinler arası yaklaşım } \\
\text { izlenmesi }\end{array}$ & 2 & 6.6 \\
\hline Diğer & 3 & 10 \\
\hline Toplam & 30 & 100 \\
\hline
\end{tabular}

Tablo 6.'da ifade edildiği gibi geleneksel çocuk oyunlarını ders kitaplarında yeterli ölçüde bulan öğretmenlerin oranı \% 26.6 olarak tespit edilmiştir. Ders kitaplarında geleneksel çocuk oyunlarını yeterli ölçüde bulmayan öğretmenlerin oranı ise \% 73.3'tür. Öğretmenler ders kitaplarında geleneksel çocuk oyunlarının yeterli seviyede bulunmasına yönelik çözüm önerileri sunmuşlardır.

Aşağıda ders kitaplarında geleneksel çocuk oyunlarını yeterli ölçüde bulmayan öğretmen görüşlerinden örnek verilmektedir:

Ö.29. "Yeterli ölçüde olduğunu düşünmüyorum. Bu durumun temel nedeni ise ilkokullarda olmak üzere bütün ders kitaplarının akademik kazanımlarla doldurulmasıdır. Benim düşünceme göre yapılması gereken öğretim sürecinin her kademesine yönelik ana kazanımların belirlenmesi ve ögrretim faaliyetlerinin bu ana kazanımlar etrafında derinleştirilmesidir. Böylelikle öğretmen-öğrenci üzerindeki ders yükü azalacak geleneksel çocuk oyunlarının öğretilmesine yeteri kadar zaman kalacaktır."

Tablo 7'de öğretmenlerin sunmuş oldukları çözüm önerileri olarak ders kitabının içeriği oyun yönünden zengin olmalı \% 23.3 , daha fazla oyun etkinliklerine yer verilmeli $\% 20$, oyun etkinlik 
kartlarının olması \% 13.3, serbest zaman etkinliklerinin oyunlarla zenginleştirilmesi \% 13.3, teorikten uygulamaya dönük olması \% 10, geleneksel çocuk oyunlarıyla ilgili kurslar açılması ve disiplinler arası yaklaşım izlenmesi \% 6.6 ile eşit seviyede çözüm önerisi olarak sunulmuştur. Öğretmenler tarafından diğer çözüm önerileri de sunulmuştur. Bu çözüm önerisinin oranı ise \% $10^{\prime}$ dur.

Geleneksel çocuk oyunlarını ders kitaplarında yeterli seviyede bulun öğretmen görüşlerini aşağıdaki gibi ifade etmiştir:

Ö.17. "Bence yeterli seviyede. Teorik olarak her türlü bilgi verilmiş. Daha fazla yer verilmesi durumunda işlenmesi gereken çok sayıdaki kazanım yetişmemiş olacak buda programın aksamasına sebep olacak. Oynamak isteyen çocuk kitapta yer alan teorik bilgilerden yola çıkrak oyunu öğrenir ve oynar. "

Öğretmenlerin bir bölümü ders kitaplarında geleneksel çocuk oyunlarını yeterli seviyede bulmaktadır. Yeterli seviyede bulan öğretmenler sebep olarak; ders kitabının teorik bilgilerle yoğun olduğu, her kazanıma belli bir süre ayrıldığı, geleneksel çocuk oyunlarına daha fazla yer verilmesi durumunda diğer kazanımların yetişmeyeceği, çocuk oyun oynuyorum diye diğer kazanımlara odaklanamayacağı bununda zaman kaybına neden olacağı şeklinde ifade etmişlerdir.

Geleneksel çocuk oyunlarıyla öğrencilerde en fazla kazandırmayı amaçladığınız değerler hangileridir? Sorusuyla alakalı Tablo 8 ve Tablo 9'da verilerin analiz edilmesi sonucunda ortaya çıkan bulgulara yer verilmiştir.

Tablo 8. Öğretmenlerin geleneksel çocuk oyunlarıyla öğrencilerde en fazla kazandırmayı amaçladıkları değerlerle ilgili görüşlerini ifade eden yanıtların frekans ve dağılım tablosu

\begin{tabular}{lll}
\hline $\begin{array}{l}\text { Kazandırılması } \\
\text { amaçlanan değer }\end{array}$ & $\mathbf{f}$ & $\mathbf{\%}$ \\
\hline Sevgi & 9 & 18 \\
\hline Adalet & 7 & 14 \\
\hline Saygı & 6 & 12 \\
\hline Sorumluluk & 6 & 12 \\
\hline Dayanışma & 6 & 12 \\
\hline Yardımseverlik & 5 & 10 \\
\hline Dürüstlük & 4 & 8 \\
\hline Eşitlik & 3 & 6 \\
\hline Diğer & 4 & 8 \\
\hline Toplam & 50 & 100 \\
\hline
\end{tabular}

Tablo 9. Öğretmenlerin geleneksel çocuk oyunlarıyla öğrencilerde en fazla kazandırmayı amaçladıkları değerlerin öğrencilere sağlayacağı yararlarla ilgili görüşlerinin ifade edildiği yanıtların frekans ve dağılım tablosu

\begin{tabular}{lll}
\hline Yararları & f & \% \\
\hline Birlik ve beraberlik sağlaması & 6 & 20 \\
\hline Kültür aktarımı & 5 & 16.6 \\
\hline Değerlerin kalıcı olarak öğrenilmesi & 5 & 16.6 \\
\hline
\end{tabular}




\begin{tabular}{lll}
\hline Farklılıklara saygı & 4 & 13.3 \\
\hline Görev ve sorumluluk alma & 3 & 10 \\
\hline Sorunlara pratik çözümler üretme & 2 & 6.6 \\
\hline Kendini gruba ait hissetme & 2 & 6.6 \\
\hline Diğer & 3 & 10 \\
\hline Toplam & 30 & 100 \\
\hline
\end{tabular}

Geleneksel çocuk oyunlarıyla öğretmenler çocuklarda en fazla kazandırmayı amaçladıkları değerler Tablo 8'de sunulmuştur. Bu değerler -sırası ile- sevgi, adalet, saygı, sorumluluk, dayanışma, yardımseverlik, dürüstlük ve eşitliktir.

Öğretmenlerin geleneksel çocuk oyunlarıyla öğrencilerde en fazla kazandırmayı amaçladıkları değerler ve çocuklara sağladığı yararlarıyla ilgili öğretmen görüşleri aşağıda verilmiştir.

Ö.22. " Saygı. Çocuk oyun sürecinde kazansa da kaybetse de karşısındaki kişiye saygı duymayı bu şekilde de farklılıklara saygılı olmayı öğreniyor."

Ö.10. "Son zamanlarda değerlerimizi yavaş yavaş kaybetmeye başlayan bir toplum olduk. Her akşam televizyonlara da yansıyan okullarda şiddetin ve çocuklarda suç oranlarının artmasından dolayı öğrencilere her şeyden önce sevgiyi, eşitliği, adaletli olmayı öğretmeyi amaçlıyorum."

Öğretmenlerin görüşleri doğrultusunda geleneksel çocuk oyunlarıyla öğrencilerde en fazla kazandırmayı amaçladıkları değerlerin çocuklara sağladığı yararlar tablo 9. da sunulmuştur. Öğretmenlerin görüşleri doğrultusunda çocuklarda birlik ve beraberlik sağlaması \% 20, kültür aktarımı ve değerlerin kalıcı olarak öğrenilmesi \% 16.6 ile eşit oranda, farklılıklara saygı \% 13.3, görev ve sorumluluk alma \% 10, sorunlara pratik çözümler üretme ve kendini gruba ait hissetme \% 6.6 ile eşit seviyede, \% 10 oranında da diğer yararları olacağı öğretmenler tarafından düşünülmektedir.

\section{Tartışma, Sonuç ve Öneriler}

Çalışma grubunu oluşturan öğretmenlerin tamamı geleneksel çocuk oyunlarını değerler eğitimi açısından önemli gördüklerini belirtmektedir. Öğretmenler; kültürün gelecek kuşaklara aktarımı, çocukların yardımlaşma, dürüstlük, saygı, sevgi, sorumluluk gibi değerleri öğrenmeleri, çocuklar arasında olumlu iletişimin gelişmesi, işbirlikçi öğrenmeyi sağlaması, farklılıklara saygı duymayı, değerlerin oyunlarla eğlenceli hale getirilmesi gibi sebeplerle geleneksel çocuk oyunlarını değerler eğitimi açısından öğretmenlerin önemli gördükleri sonucuna ulaşılmıştır. Öğretmenlerin geleneksel çocuk oyunlarını değerler eğitimi açısından önemli gördüklerine dair benzer sonuçlara ulaşılımışır. Esen (2008), çalışmasında geleneksel çocuk oyunları Türk toplumunun gelenek ve göreneklerini yansıtarak kültürün devamlılı̆ını sağladığını belirtmiştir. Thompson vd. (2014), yapmış oldukları çalışmada toplumla ilişkili geleneksel oyunlar kültürel mirasın ve sosyal kimliklerinin yeterli bir yansıması olarak kabul edilmektedir. Tarihsel olarak oynanan oyunlar, hayatta kalma becerilerini ve günlük yaşamının özelliklerini öğretmek için bir araçtır. Bununla birlikte bu oyunlar toplumlarda sosyal bağları güçlendirme, kültürleri paylaşma ve geleneksel bilgileri aktarmada önemli olduğu belirtilmiştir. Sümbüllü ve Altınışık (2016), yapmış oldukları çalışmada geleneksel çocuk oyunlarının çocukları geleceğe hazırladığı, toplumsal değerleri oyunlar mevcut biçimde sunarak içerisinde 
barındırdığı toplumsal değerlerin güvenli ve kolay bir şekilde verildiği yer olduğu sonucuna ulaşıımıştır. Öz Pektaş ( 2017), yaptığı çalışmada oyunlar içinde yaşadığımız toplumun kültür yapısını ve özelliklerini taşıdığı, oyunlar kültürel değerlerin nesilden nesile aktarılmasını sağlayarak eğitimöğretimde etkili bir yöntem olarak kullanıldığı belirlenmiştir. Bay (2018), çalışmasında ailelerde oynanan milli oyunlar yoluyla kültürel mirasımız nesilden nesile aktarıldığı tespit edilmiştir.

Geleneksel çocuk oyunlarının değerler eğitimi açısından okul öncesi dönemde oynatılması katılımcıların çoğunluğu tarafından ifade edilmiştir. Eğitim basamaklarından okul öncesi dönemde oynatılması gerektiğini düşünen öğretmenlerin gerekçeleri; çocukların daha hızlı ve kalıcı öğrendiği dönem, kişilik gelişiminin geliştiği zaman, kültürün içselleştirilmesinin sağlandığı dönem, psikomotor ve duyuşsal becelerin kazanıldığı zaman, bireysel farklılıklara saygının kazanıldığı dönem, grup olma bilincinin kazanıldığı zaman, çocuğun hayatı anlamlandırdığı zaman gibi sebeplerden dolayı geleneksel çocuk oyunlarının okul öncesi dönemde oynatılmasının olumlu olacağı sonucuna ulaşılmıştır. Bay (2018), yaptığı araştırmada okul öncesi öğretim programı çerçevesinde ulusal oyunların kolaylıkla kazandırılabildiği ve çocuklara ulusal kültürün önemli faktörü olan oyunların gelişimlerine olumlu yönde katkı sağladığı görünmektedir. Millî oyunlar, Türkçe, Matematik, Fen, Müzik, Sanat gibi farklı etkinlikler ile entegreleştirilmiş aktiviteler halinde uygulanmış ve çocukların özbakım, fiziksel, dilsel, bilişsel ve sosyal becerilerini destekleyerek çocukların duygu ve düşünceleri üzerinde etkili olduğu, okul öncesinin çocuklar için eğitim ve kültürel gelişim bakımından kritik bir evre olduğu milli oyunların bilme, kavrama ve uygulama basamaklarına katkı sağladığı tespit edilmiştir. Akandere (2004), çalışmasında okul öncesi dönem de milli oyunlarımızdan 5 taş oyununun dikkat ve göz koordinasyonu sağladığı çocukların becerilerinin gelişimini destekleyen millî bir oyun olduğu sonucuna ulaşımıştır. Kurniawati vd. (2014), yapmış oldukları çalışmada geleneksel oyunların, küçük çocuklara değer eğitiminde erken yaşta köprü olarak kullanabileceği, oyunların yerel bilgeliklerden biri olduğu ve değer aktarmanın bir yolu olduğu tespit edilmiştir. Geleneksel çocuk oyunlarının değerler eğitimi açısından okul öncesi dönemde oynatılması araştırma sonuçlarıyla benzer olduğu görülmüştür.

Geleneksel çocuk oyunlarıyla öğrencilerin birden fazla değeri kazandıkları sonucuna ulaşıımıştır. Öğretmenler öğrenciler tarafından kazandıklarını gözlemledikleri değerler saygı, sevgi, adalet, dayanışma, yardımlaşma, dürüstlük, eşitlik, sorumluluk, estetik ve barıştır. Öğretmenler geleneksel çocuk oyunlarıyla gözlemledikleri değerlerin daha kolay kazanıldığını ifade etmişlerdir. Zayyadi vd. (2018), yapmıs oldukları çalışmada geleneksel oyunlar çocuklarda yaratıcılık, sosyal etkileşim, işbirliği, sportmenlik, dürüstlük ve yaratıcılık değerlerini öğrendikleri sonucuna ulaşılmıştır. Dharmamulya (2005), çalışmasında çocukların geleneksel oyunlarda öğrendikleri kültürel değerler; dostluk, demokrasi, liderlik, sorumluluk, paylaşma, yardımlaşma, düşünme becerilerini uygulama ve dürüstlük olduğunu tespit etmiştir. MEB [2018), sosyal bilgiler öğretim programında yer alan değerler; adalet, çalışkanlık, aile birliğine önem verme, dayanışma, bağımsızlık, bilimsellik, barış, dayanışma, estetik, duyarlıık, eşitlik, dürüstlük, sorumluluk, özgürlük, tasarruf, saygı, vatanseverlik sevgi, tasarruf ve yardımseverliktir. MEB [2018), Türkçe öğretim programında kök değerler; öz denetim, sabır, adalet, dürüstlük, dostluk, saygı, sorumluluk, sevgi, vatanseverlik ve yardımseverliktir. Öğretim programlarında yer alan değerlerin geleneksel çocuk oyunlarıyla kazandırılabileceği sonucuna ulaşılmıştır.

Geleneksel çocuk oyunlarını ders kitaplarında öğretmenlerin çoğunluğu yeterli ölçüde bulmamaktadır. Yeterli seviyede bulmayan öğretmenler; ders kitabının içeriği oyun yönünden zengin 
olmalı, daha fazla oyun etkinliklerine yer verilmeli, oyun etkinlik kartlarının olması, serbest zaman etkinliklerinin oyunlarla zenginleştirilmesi, teorikten uygulamaya dönük olması, geleneksel çocuk oyunlarıyla ilgili kurslar açılması ve disiplinler arası yaklaşım izlenmesi gibi çözüm önerisi sunmuşlardır. Geleneksel çocuk oyunlarını ders kitaplarında öğretmenlerin bir kısmı yeterli ölçüde bulmaktadır. Yeterli seviyede bulan öğretmenler sebep olarak; ders kitabının teorik bilgilerle yoğun olduğu, her kazanıma belli bir süre ayrıldığı, geleneksel çocuk oyunlarına daha fazla yer verilmesi durumunda diğer kazanımların yetişmeyeceği, çocuk oyun oynuyorum diye diğer kazanımlara odaklanamayacağı bununda zaman kaybına neden olacağı şeklinde ifade etmişlerdir. Duran ve Tufan (2017) yapmış oldukları çalışmada, oyunlarla ilgili illkokul 1. 2. 3. ve 4. sınıf Türkçe ders kitapları incelenmiştir. Birinci ve ikinci sınıf ders kitabında dört oyun, üçüncü sınıf kitabında beş oyun, dördüncü sınıf kitabında ise üç oyun olduğu sonucuna ulaşılmıştır. Sınıflardaki oyun ve oyuncak sayıları bakımdan bir tutarlılık olmadığı, oyuna ve oyuncağa alakanın üst düzeyde olduğu ilkokul döneminde yeterince oyuncak ve oyunun Türkçe kitaplarında eğitsel gayede yer verilmediği belirlenmiştir. Türkçe kitaplarında oyunların hem sayısal hem de kategori olarak çeşitlendirilmesi gerektiği ve ders kitaplarında bulunan oyunların yeterli olmadığı sonucuna ulaşılmıştır. Ünal (2013), yapmış olduğu çalışmada sosyal bilgiler 4. sınıf öğretim programında kültür kavramıyla alakalı kazanım sayısının fazla olduğu belirlenmiştir. Sosyal bilgiler ders ve çalışma kitaplarında halk kültürü ögelerinin bütün kategorileri ile ilgili örneklere yer verilmediği görülmüştür. Sosyal bilgiler çalışma ve ders kitaplarında halk kültürü ögelerinin tümüyle ilgili örnekler yer almamaktadır. Özellikle, sosyal bilgilerin sosyal bilimlerle alakalı konulara disiplinler arası bir bakış açısıyla yaklaşması sebebiyle kazanımlarda kültüre ait bir ifade bulunmadığı tespit edilmiştir. Sonuçlar araştırma sonucuyla benzer niteliktedir.

Geleneksel çocuk oyunlarıyla öğretmenlerin çocuklarda en fazla kazandırmayı amaçladıkları değerler sevgi, adalet, saygı, sorumluluk, dayanışma, yardımseverlik, dürüstlük ve eşitliktir. Öğretmenler geleneksel çocuk oyunlarıyla öğrencilerde kazandırmayı amaçladıkları değerlerle; birlik ve beraberlik sağlama, kültür aktarımı, değerlerin kalıcı olarak öğrenilmesi, farklılıklara saygı, görev ve sorumluluk alma, sorunlara pratik çözümler üretme ve kendini gruba ait hissetme gibi çocuklarda yararlar sağlayacağı sonucuna ulaşılııştır. Çengelci vd. (2013), yaptıkları araştırmada öğretmenlerin okulda kazandırmaya çalıştığı değerler hoşgörü, sevgi, dayanışma, saygı ve sorumluluk olduğu sonucuna ulaşıımıştır. Sümbüllü ve Altınışık (2016), çalışmasında değerler kuşaktan kuşağa oyunlar yoluyla aktarılır. Çocuk oyun yoluyla toplumun sahip olduğu değerlerin farkına vararak kendinden sonra gelecek nesillere kültürün aktarılmasında oyunların aktif rol oynadığı tespit edilmiştir. Fedakâr ve Korkutan (2016), yaptıkları çalışmada ödül ve ceza oyunun yapısı içerisinde yer alır. Geleneksel çocuk oyunlarıyla çocuklar rekabet ve yarışmadan daha ziyade ortak bir paylaşımda bulunularak eğlence işlevi gördüğü sonucuna ulaşılmıştır. Apay (2016), yaptığı çalışmada çocuklar oyun yoluyla birçok değerden haberdar olacak bu sayede daha zengin bir kişilik geliştirebileceği belirtilmiştir. Esen (2008), çalışmasında çocukların oynamış oldukları oyunlar sosyal gelişmelerine katkı sağlar. Kuralın farkına varma, kurallara uyma, kendini gruba ait hissetme, ortak grup kararına uyma gibi kavramların öğrenilmesine olumlu yönde katkı sağladığı tespit edilmiştir. Thompson vd. (2014), yapmış oldukları çalışmada geleneksel oyunlar ekip çalışması, işbirliği duygusunu geliştirme, sağlamlaştırılmış iç ilişkiler kurma ve sosyal ilişkileri güçlendirmede toplumda kilit bir odak noktası olduğu belirtilmiştir. Akbulut (2009), araştırmasında oyunun çocuğun olgunlaşma ve gelişimine katkı sağladığı ifade edilmiştir. Oyun sayesinde çocuğun yaratıcılı̆̆ı, duygusal ve entelektüel yönden gelişimini desteklediği tespit edilmiştir. Dehkordı (2017), Persler geleneksel oyunları yüce gönüllülük, adalet, ahlak, sabır, 
dostluk karşılıklı anlayış, fedakarlık dürüstlük, alçakgönüllülük, sadakat, insanlık, özveri, cesaret ve terbiye teşvik etmek için kullandıkları ve bu değerleri diğer milletlere yaymak için ellerinden geleni yaptıkları belirtilmiştir. Sümbüllü ve Altınışık (2016), yapmış oldukları çalışmada oyunlar çocuğun sosyal ve kültürel bakımdan gelişmesini sağlar. Çocuk oyun oynarken saygı, sevgi, dayanışma, yardımlaşma, dürüstlük, dostluk, paylaşma, iyilik, kötülük, haklıık, haksızlık, kurallara uyma gibi bir çok kültürel ve sosyal değerleri oyun ortamında öğrendiği sonucuna ulaşılmıştır. Geleneksel çocuk oyunlarıyla öğretmenlerin çocuklarda en fazla kazandırmayı amaçladıkları değerler ve çocuklara sağladığı yararlar bakımından benzer sonuçlara ulaşılmıştır.

Geleneksel çocuk oyunlarının, etkinliklerle okul öncesi dönemden itibaren öğrencilere öğretilmesi, sınıf öğretmenlerinin serbest zaman etkinliklerinde bu oyunları oynatmaları ve tüm derslerle ilişkilendirmeleri öğrencilerin değerleri daha kolay içselleştirmelerini sağlayabilir. Geleneksel çocuk oyunlarını öğrenciler yalnızca okulda değil, okul dışında da gerçekleştirebilecekleri etkinlikler hazırlanabilir. Geleneksel çocuk oyunlarına ders kitaplarında etkinlikler ve görsellerle zenginleştirilerek daha fazla yer verilebilir. 


\section{Kaynakça}

Akbulut, H. (2009). Dijital oyun rehberi. İstanbul: Kalkedon Yayınları.

Akandere, M. (2004). Eğitici okul oyunları. Ankara: Nobel Yayıncılık.

Altınbulak, D., Emir, S. ve Avcı, C. (2012). Sosyal bilgiler öğretiminde eğitsel oyunların erişiye ve kalıcı lığa etkisi. HAYEF Journal of Education, 3(2), 35-51.

Aypay, A. (2016). Investigating the role of traditional children's games in teaching ten universal values in Turkey. Eurasian Journal of Educational Research, 62, 283- 300.

Bay, N. (2018). Okul öncesi eğitimde bir kültür aktarımı: Milli oyunlar. Uluslararası Eğitim Araştırmaları Dergisi, $9(2), 82-104$.

Büyüköztürk, Ş., Kılıç Çakmak, E., Akgün, Ö.E., Karadeniz, Ş ve Demirel, F. (2011). Bilimsel araştırma yöntemleri. (10.baskı). Ankara: Pegem Yayıncılık.

Cop, M., R., ve Kablan, Z. (2018). Türkiye'de eğitsel oyunlarla ilgili yapılmış çalışmaların analizi. Kocaeli Üniversitesi Eğitim Dergisi, 1(1), 52-71.

Çengelci, T., Hancı, B. ve Karaduman, H. (2013). Okul ortamında değerler eğitimi konusunda öğretmen ve öğrenci görüşleri. Değerler Eğitimi Dergisi, 11(25), 33-56.

Dehkordı, M. R. (2017). The educational ımpact of traditional games: the role of Zurkhaneh sport in educating children . International Journal of Sport Culture and Science, 5(3), 134-139.

Dharmamulya, S. (2005). Permainan Tradisional Jawa. Yogyakarta: Kepel Press.

Duran, E. ve Tufan, B. (2017). Illkokul Türkçe ders kitaplarında oyun ve oyuncakların kullanımı. Ahi Evran Üniversitesi Sosyal Bilimler Enstitüsü Dergisi (AEÜSBED), 3(1), 16-28.

Esen, M. A. (2008). Geleneksel çocuk oyunlarının eğitimsel değeri ve unutulmaya yüz tutmuş Ahıska oyunları. Uludağ Üniversitesi Eğitim Fakültesi Dergisi, 21(2), 357-367.

Fedakâr, P. ve Korkutan, S. (2016). Seferihisar geleneksel çocuk oyunlarının yapısal analizi. Pamukkale Üniversitesi Sosyal Bilimler Enstitüsü Dergisi, 25(1), 366-374.

Ghosh, P. (2015). Traditional sports and games culture around West Bengal. International Journal of Novel Research in Humanity and Social Sciences, 2(3), 1-5.

Karataş, Z. (2015). Sosyal bilimlerde nitel araştırma yöntemleri. Manevi Temelli Sosyal Araştırma Dergisi, $1(1), 62-80$.

Kurniawati, Y., Pranoto, S., ve Hong, J. J. (2014). Indonesian journal of early childhood young children character developmen through. Javanese Traditional Game, 3(1), 54-58.

Kümbetoğlu, B. (2005). Sosyolojide ve antropolojide niteliksel yöntem ve araştırma. İstanbul: Bağlam Yayıncılık.

Milli Eğitim Bakanlığı [MEB] (2018). Sosyal Bilgiler dersi öğretim programı (illkokul ve Ortaokul 4, 5, 6 ve 7. Sınıflar). Ankara: MEB Yayınları.

Milli Eğitim Bakanlığı [MEB] (2018). Türkçe dersi öğretim programı (illkokul ve Ortaokul 1, 2, 3, 4, 5, 6, 7 ve 8. Sınıflar). Ankara: MEB Yayınları.

Pektaş, Ö. H. (2017). Geleneksel çocuk oyunlarinin modern eğitimde kullanilmasi. Journal of International Social Research, 10(49), 478-490.

Samancı, O. ve Uçan, Z. (2015). Sınıf öğretmeni adaylarının sosyal sorun çözme beceri düzeylerinin incelenmesi. Bartın Üniversitesi Eğitim Fakültesi Dergisi, XIV. Uluslararası Katılımlı Sınıf Öğretmenliği Eğitimi Sempozyumu Özel Sayısı. 152-162. 
Sümbüllü, Y. Z. ve Altınışık, M. E. (2016). Geleneksel çocuk oyunlarının değerler eğitimi açısından önemi. Erzurum Teknik Üniversitesi Sosyal Bilimler Enstitüsü Dergisi, 1(2), 73-85.

Thompson, M. D., Meldrum, K. ve Sellwood, J. (2014). “...it is not just a game”: Connecting with culture through traditional Indigenous games. American Journal of Educational Research, 2(11), 1015-1022.

Türnüklü, A. (2000). Türnüklü, A. (2000). Eğitim bilim araştırmalarında etkin olarak kullanılabilecek nitel araştırma tekniği: Görüşme. Kuram ve Uygulamada Eğitim Yönetimi. 24, 543-559.

Ünal, F. (2013). İlköğretim sosyal bilgiler ders kitaplarında yer alan halk kültürü öğelerinin değerlendirilmesi. Adıyaman Üniversitesi Sosyal Bilimler Enstitüsü Dergisi, 6(14), 611- 644.

Yıldırım, A. ve Şimşek, H. (2005). Sosyal bilimlerde nitel araştirma yöntemleri. Seçkin Yayıncılık: Ankara.

Zayyadi, M., Hasanah, S., I. ve Surahmi E. (2018). Ethnomatematics exploration in traditional games as a form of students social Interaction. JIPM (Jurnal IImiahPendidikan Matematika), 6(2), 125-132. 